\title{
Surface Plasmon Resonance Imaging Measurements of the Inhibition of Shiga-Like Toxin by Synthetic Multivalent Inhibitors
}

Vishal Kanda, Pavel Kitov, David R. Bundle and Mark T. McDermott*

Department of Chemistry, University of Alberta, Edmonton, AB, Canada T6G 2G2

\section{Supplementary Information}

\section{Synthesis of STARFISH-2}

Previously described lactose derivative $\mathbf{1}$ was deacetylated to give compound 2, which was derivatized as 4',6'-benzylidene cyclic acetal and benzoylated to give $\mathbf{3}$ and $\mathbf{4}$. Removal of acetal afforded diol $\mathbf{5}$, which was selectively benzoylated to provide glycosyl acceptor $\mathbf{6}$. Glycosylation of 6 with tetra-benzyl galactosyl chloride gave trisaccharide $\mathbf{7}$.

Benzyl protective groups are generally stable at most conditions used in glycoside chemistry. However, removal of multiple O-benzyl groups is a problem and it was desirable to replace them with more convenient ester protecting groups on the early stages of the scheme. Because of incompatibility of double bond functionality with most methods of O-benzyl removal, allylic double bond was partially processed (dihydroxylated) and protected with cyclic ketal 8 prior to trisaccharide deprotection. This maneuver has allowed to efficiently remove both benzyl and benzoyl groups by $\mathrm{Na}$ in liquid ammonia, and, after per-acetylation, acetyl protected $\mathrm{P}^{\mathrm{k}}$-trisaccharide derivative $\mathbf{9}$ was obtained. Acid treatment of $\mathbf{9}$ followed by oxidation of resulting diol with NaIO4 and reduction with $\mathrm{NaBH} 4$ provided 2-hydroxyethyl compound $\mathbf{1 0}$ which was activated as $p$-nitrophenyl carbonate to give key trisaccharide $\mathbf{1 1}$.

The linker arm containing bifurcation point was obtained by following sequence of reactions. Boc protection of 1,3-diamino-2-hydroxypropane 12 followed by activation of hydroxyl 13 as $p$-nitrophenyl carbonate gave 14, which reacted with 11-aminoundecanoic acid to give 15. Remowal of Boc protective groups and coupling with trisaccharide $\mathbf{1 1}$ afforded branched trisaccharide-terminated linker-arm $\mathbf{1 6 .}$ 
The core structure was assembled starting from penta-allyl glucose derivative 17. Radical addition of amino ethanethiol resulted in penta-amino derivative 18, each arm of which was extended by acylation with Boc glycine to give Boc protected derivative of 19. Treatment of this intermediate with TFA restored 19, which was acylated with the branched sugar-terminated linker-arm 16. Deacetylation of the reaction mixture resulted in target STARFISH analog.
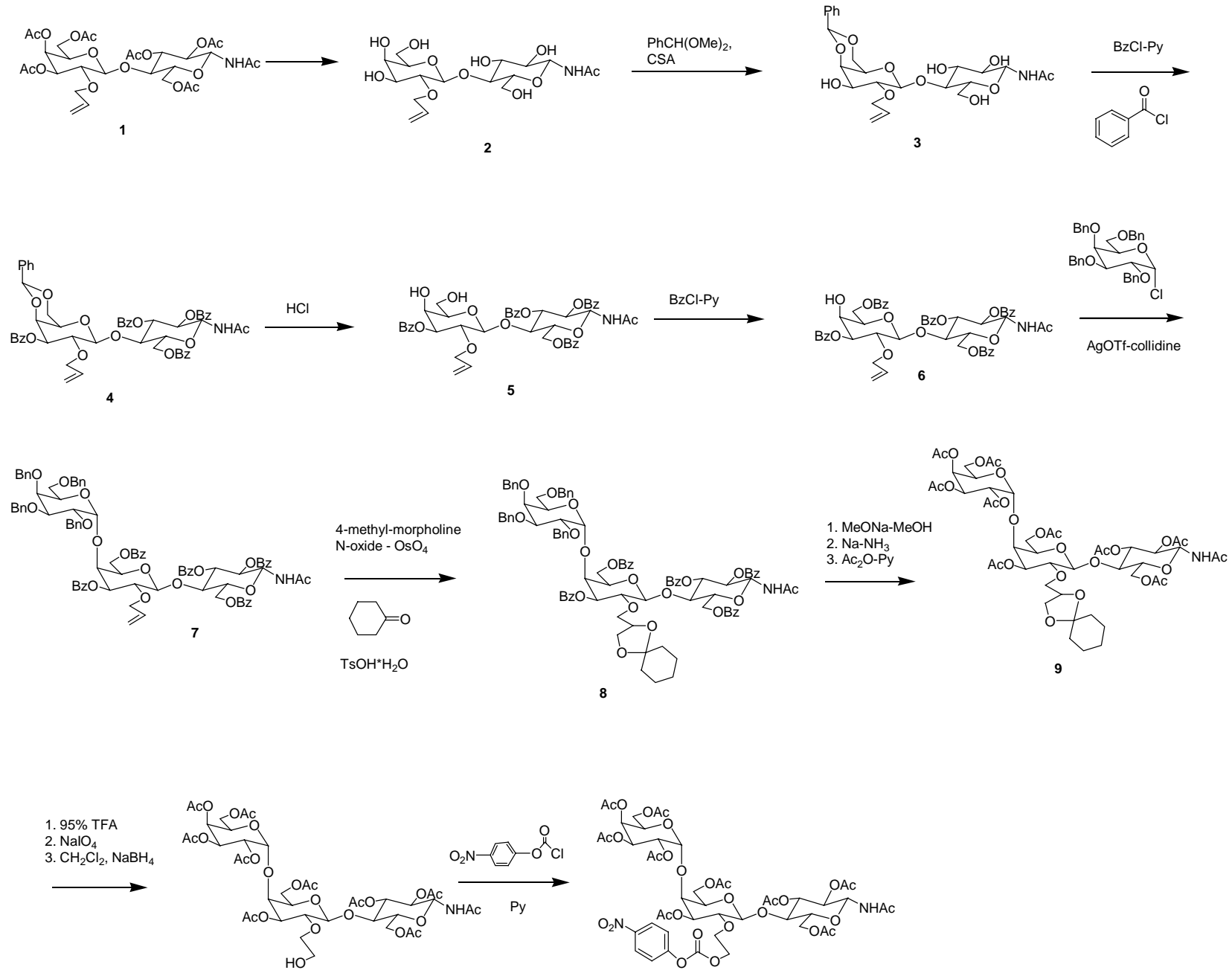

10 

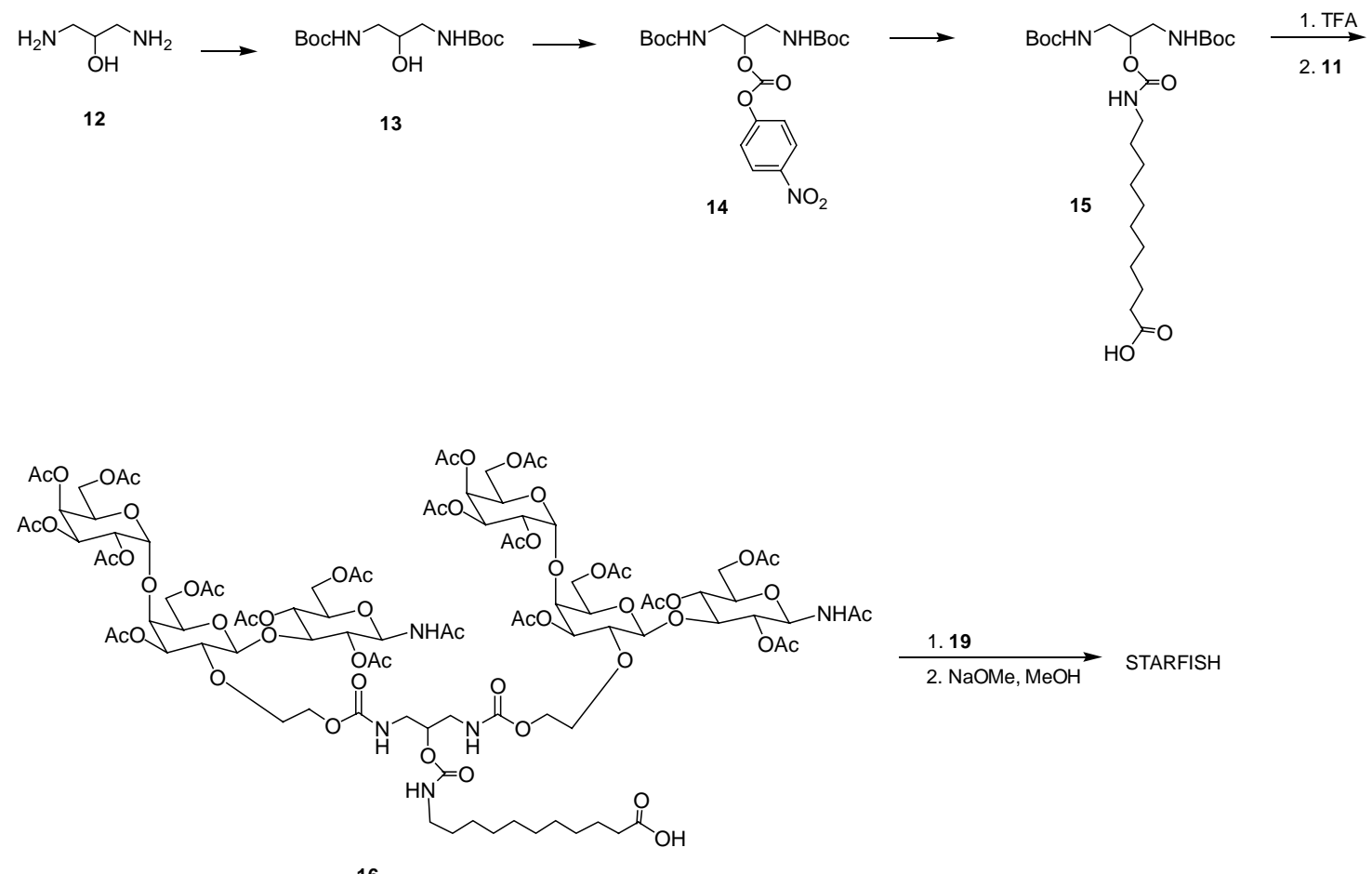

16

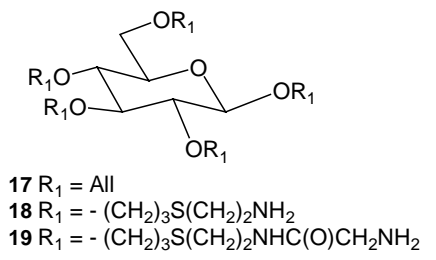

1-acetamido-1-deoxy-4-O-(2-O-allyl- $\beta$-D-galactopyranosyl)- $\beta$-D-glucopyranose (2)

Compound 1 (10.58 g) was dried, dissolved in $100 \mathrm{~mL}$ of dry $\mathrm{MeOH}$ and $\mathrm{K}_{2} \mathrm{CO}_{3}(\sim 0.5$ g) was added. After $16 \mathrm{~h}$ at $40^{\circ} \mathrm{C}$ the mixture was conc. Dissolved in water, neutralized with $2 \mathrm{~g}$ of DOWEX $\left(\mathrm{H}^{+}\right)$and concentrated. Crystallization from EtOH afforded 2 (95\%).TLC: DCM-MeOH (2:1), $\mathrm{R}_{\mathrm{f}} \sim 0.5 .{ }^{1} \mathrm{H}-\mathrm{NMR}\left(\mathrm{D}_{2} \mathrm{O}\right): \delta$ 6.05-5.9 (m, $\left.1 \mathrm{H}, \mathrm{All}\right), 5.4-$ 5.25 (m, 2 H, All), 5.00 (d, 1 H, J,2 9.1 Hz, H-1), 4.50 (d, 1 H, J $1_{1,2}, 7.9$ Hz, H-1'), 4.364.24 (m, 2 H, All), 3.94-3.91 (m, 2 H, H-6a, H-4), 3.82 - 3.66 (m, 8 H, H-3, H-5, H-6b, H-3’, H-4', H-5’, H-6’a,H-6’b), 3.46-3.42 (m, 2 H, H-2, H-2'), 2.09 (3 H, NAc).

Synthesis of 1-acetamido-1-deoxy-4-O-(2-O-allyl-3-O-benzoyl- $\beta$-D-galactopyranosyl)2,3,6-tri-O-benzoyl- $\beta$-D-glucopyranose (5)

Compound 2 (6.27 g, $14.8 \mathrm{mmol}$ ) was suspended in dry MeCN (160 mL), PhCH(OMe) (2.66 mL) and D,L-10-camphorsulfonic acid ( 200 mg) was added. The mixture was 
sonicated with occasional shaking for $1 \mathrm{~h}$. the precipitate has changed in appearance. For monitoring of the reaction sample with precipitate was taken. TLC: DCM-MeOH (2:1), $\mathrm{R}_{\mathrm{f}} \sim 0.9$. After the reaction was complete dry pyridine (14 mL) and slowly BzCl $(15 \mathrm{~mL})$ was added. TLC: hexane-ethyl acetate $(1: 1), \mathrm{R}_{\mathrm{f}} \sim 0.3$. After $16 \mathrm{~h}$ the reaction was quenched with $\mathrm{MeOH}$, concentrated, co-evaporated with toluene 3 times and dried. The residue (4) was dissolved in $80 \% \mathrm{AcOH}(100 \mathrm{~mL})$ and stirred at $90^{\circ} \mathrm{C}$ for $4 \mathrm{~h}$ then diluted with brine, extracted with $\mathrm{DCM}$, washed with saturated $\mathrm{NaHCO}_{3}$ and concentrated. Chromatography on silica gel with hexane:acetone $=70: 30-50: 50$ gave $5(9 \mathrm{~g}, 72 \%) .{ }^{1} \mathrm{H}$ NMR (CDCl $)$ ): $\delta$ 8.10-7.90 and 7.60-7.30 (m, 20 H, Bz), 6.37 (d, 1 H, J, $\mathrm{J}_{1, \mathrm{NH}} 9.1 \mathrm{~Hz}, \mathrm{NH}$ ), 5.82 (t, $1 \mathrm{H}, \mathrm{J}_{2,3} \sim \mathrm{J}_{3,4}=9.5 \mathrm{~Hz}, \mathrm{H}-3$ ), 5.76-5.70 (m, $1 \mathrm{H}$, All), 5.48 (t, $1 \mathrm{H}, \mathrm{J}_{1,2} \sim \mathrm{J}_{1, \mathrm{NH}}=$ 9.3 Hz, H-1), 5.30 (t, 1 H, J $\mathrm{J}_{1,2} \sim \mathrm{J}_{2,3}=9.7 \mathrm{~Hz}, \mathrm{H}-2$ ), 5.14-5.11 (broad d, $1 \mathrm{H}$, All), 5.00

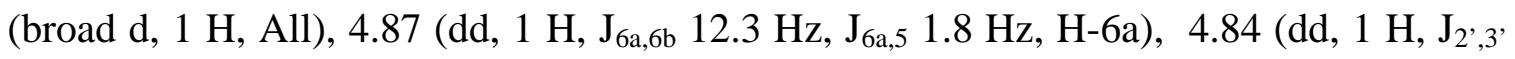

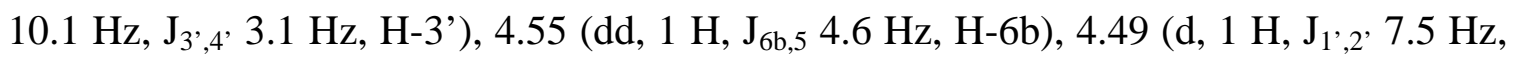
H-1'), 4.24-4.21 (m, 1 H, All), 4.20 (t, 1 H, J4,5 9.3 Hz, H-4), 4.15-4.10 (m, 1 H, All), 4.06-4.02 (m, 1 H, H-5), 4.03 (d, 1 H, H-4'), 3.72 (dd, 1 H, H-2'), 3.28 (dd, 1H, J J'a,6’b 11.5 Hz, J' 6’a,5 $^{\prime} 3.5$ Hz, H-6’a), 3.23-3.18 (m, 2 H, H-5', H-6’b), 1.90 (3 H, NAc).

1-acetamido-1-deoxy-4-O-(2-O-allyl-3,6-di-O-benzoyl- $\beta$-D-galactopyranosyl)-2,3,6-triO-benzoyl- $\beta$-D-glucopyranose (6)

To a solution of 5 (3.57 g, $4.25 \mathrm{mmol})$ in DCM (20 mL) and dry pyridine (1.03 mL) BzCl (1eq., $0.566 \mathrm{~mL}$ ) was slowly added at $0^{\circ} \mathrm{C}$. After $1 \mathrm{~h}$ the reaction was quenched with $\mathrm{MeOH}$, concentrated and co-evaporated with pyridine 3 times. Chromatography with hexane:ethyl acetate $=55: 45-50: 50$ gave $6(3.3 \mathrm{~g}, 82 \%) .{ }^{1} \mathrm{H}-\mathrm{NMR}\left(\mathrm{CDCl}_{3}\right): \delta$ 8.10-7.90 and 7.60-7.30 (m, 25 H, Bz), 6.40 (d, 1 H, J $\left.\mathrm{J}_{1, \mathrm{NH}} 9.1 \mathrm{~Hz}, \mathrm{NH}\right), 5.86\left(\mathrm{t}, 1 \mathrm{H}, \mathrm{J}_{2,3} \sim \mathrm{J}_{3,4}=9.5\right.$ Hz, H-3), 5.77-5.70 (m, 1 H, All), 5.48 (t, 1 H, J $\left.\mathrm{J}_{1,2} \sim \mathrm{J}_{1, \mathrm{NH}}=9.3 \mathrm{~Hz}, \mathrm{H}-1\right), 5.27$ (t, $1 \mathrm{H}$, H-2), 5.18-5.14 (m, 1 H, All), 5.04-5.01 (m, 1 H, All), 4.91 (dd, 1 H, J $2^{\prime}, 3^{\prime}$ 10.1, Hz, J $3^{\prime}, 4^{\prime}$ 3.3 Hz, H-3'), 4.86 (dd, 1 H, Jaa,6b 12.3 Hz, J Ja, 1.8 Hz, H-6a), 4.56 (dd, 1 H, J Jb,5 4.2 Hz, H-6b), 4.51 (d, 1 H, J', ${ }^{\prime}, 2.7$ Hz, H-1'), 4.26-4.22 (m, 2 H, H-4, All), 4.15-4.13 (m, 1

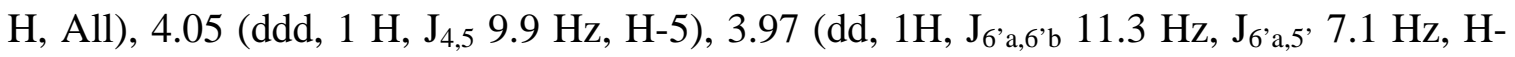
6'a), 3.95 (d, 1 H, H-4'), 3.71-3.66 (m, 2 H, H-2', H-6'b), 3.55 (broad t, 1 H, H-5'), 1.90 (s, 3 H, NAc). 
1-acetamido-1-deoxy-4-O-[2-O-allyl-3,6-di-O-benzoyl-4-O-(2,3,4,6-tetra-O-benzyl- $\alpha$-Dgalactopyranosyl)- $\beta$-D-galactopyranosyl]-2,3,6-tri-O-benzoyl- $\beta$-D-glucopyranose (7) A mixture of 6 (3.3 g, $3.49 \mathrm{mmol})$ and AgOTf (1.97 g, 2.2 eq.) was suspended in $15 \mathrm{~mL}$ of dry toluene, then 2,4,6-collidine (1.03 $\mathrm{mL}, 2.2$ eq.) was added and the mixture was cooled to $0^{\circ} \mathrm{C}$. A solution of 2,3,4,6-tetra-O-benzyl- $\alpha, \beta$-D-galactopyranosides (5.2 g) in dry toluene $(10 \mathrm{~mL})$ was added slowly and the reaction was stirred for $1 \mathrm{~h}$. TLC: a sample was taken by pipette, diluted with $\sim 0.2 \mathrm{~mL}$ of ethyl acetate, washed with $1 \mathrm{~N} \mathrm{HCl}$, TLC performed in hexane:ethyl acetate $=1: 1, \mathrm{Rf}=0.5$. The mixture was diluted with toluene, washed with saturated $\mathrm{Na}_{2} \mathrm{~S}_{2} \mathrm{O}_{3}, 10 \% \mathrm{HCl}$, water, and $\mathrm{NaHCO}_{3}$ then concentrated. Chromatography with hexane : ethyl acetate $=65: 35-50: 50$ gave 7 (3.7 g, 72\%). ${ }^{1} \mathrm{H}-\mathrm{NMR}\left(\mathrm{CDCl}_{3}\right): \delta$ 8.10-7.00 (m, $45 \mathrm{H}$, arom), 6.40 (d, $\left.1 \mathrm{H}, \mathrm{J}_{\mathrm{NH}, 1} 9.2 \mathrm{~Hz}, \mathrm{NH}\right)$, 5.89 (t, $\left.1 \mathrm{H}, \mathrm{J}_{2,3}=\mathrm{J}_{3,4}=9.52 \mathrm{~Hz}, \mathrm{H}-3\right), 5.70-5.64$ (m, $1 \mathrm{H}$, All), 5.48 (t, $1 \mathrm{H}, \mathrm{J}_{1,2} 9.3 \mathrm{~Hz}$, H-1), 5.20 (t, 1 H, J2,3 9.5 Hz, H-2), 5.04 (dd, 1 H, J 17.2 Hz, J 1.3 Hz, All), 4.93-4.91 (m, 1 H, All), 4.88 (dd, 1 H, J Ja,6b 12.5 Hz, J,6a 1.6 Hz, H-6a), 4.84 (dd, 1 H, J', ${ }^{\prime}, 10.3$ Hz,

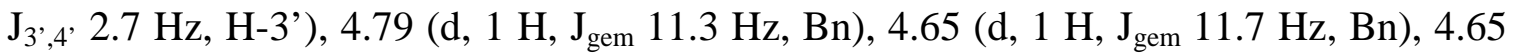

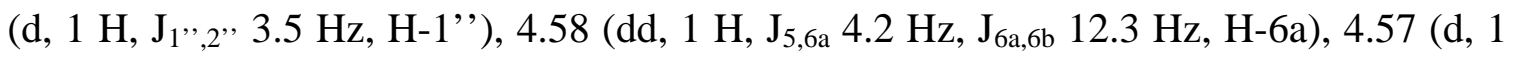

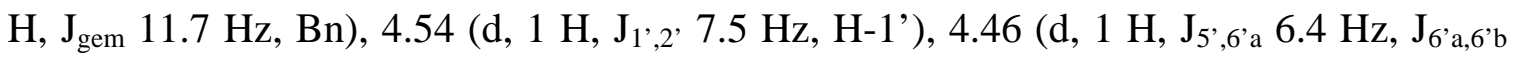
11.3 Hz, H-6’a), 4.43 (d, 1 H, Jgem 11.2 Hz, Bn), 4.43 (s, 2 H, Bn), 4.25-4.10 (m, 6 H, H4, H-4', H-6’b, Bn, All), 4.06-4.02 (m, 2 H, H-5, All), 3.95 (broad t, 1 H, J 6.8 Hz, H5'), 3.84 (broad s, 1 H, H-4'”), 3.79 (dd, 1 H, J2",3" 10.3 Hz, H-2'), 3.67-3.62 (m, 3 H,

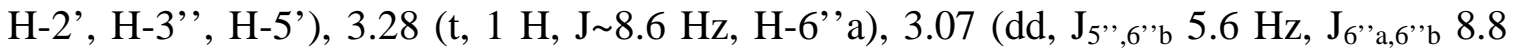
Hz, H-6’'b), 1.9 (s, 3 H, NHAc).

1-acetamido-1-deoxy-4-O-[2-O-(R,S-2,3-cyclohexylidendioxypropyl)-3,6-di-O-benzoyl-4O-(2,3,4,6-tetra-O-benzyl- $\alpha$-D-galactopyranosyl)- $\beta$-D-galactopyranosyl]-2,3,6-tri-Obenzoyl- $\beta$-D-glucopyranose (8)

To a solution of 7 (1.28 g, $0.87 \mathrm{mmol})$ and 4-methyl-morpholine N-oxide (205 mg) in 10 $\mathrm{mL}$ of acetone $1 \mathrm{~mL}$ of $\mathrm{OsO}_{4}$ solution in $\mathrm{t}-\mathrm{BuOH}$ was added. The reaction was stirred at $40{ }^{\circ} \mathrm{C}$ for $1 \mathrm{~h}$ then diluted with DCM and washed with water, concentrated. The product was used for the next step without further purification. The residue was dried in vacuum overnight then dissolved in $\mathrm{MeCN}$, cyclohexanon (4 mL) and $\mathrm{TsOH}$ (cat.) were added and the reaction mixture was heated at $50^{\circ} \mathrm{C}$ for $0.5 \mathrm{~h}$, then neutralized by $\mathrm{Et}_{3} \mathrm{~N}$, 
concentrated and chromatographed on silica gel with hexane:ethyl acetate $=70: 30-60: 40$ gave 8 (1.17 g, 85\%).

1-acetamido-1-deoxy-2,3,6-tri-O-acetyl-4-O-[2-O-(R,S-2,3-cyclohexylidendioxypropyl)3,6-di-O-acetyl-4-O-(2,3,4,6-tetra-O-acetyl- $\alpha$-D-galactopyranosyl)- $\beta$-Dgalactopyranosyl]- $\beta$-D-glucopyranose (9)

To a solution of 8 (3.35 g, $2.11 \mathrm{mmol})$ in dry $\mathrm{MeOH}(10 \mathrm{~mL})$ and dry $\mathrm{K}_{2} \mathrm{CO}_{3}(\sim 50 \mathrm{mg})$ was added the mixture was stirred for 2 days then neutralized by DOWEX, filtered and concentrated. The product was briefly columned on silica gel (10\% MeOH-DCM at the end) to remove BzOMe, concentrated and dried. The residue was dissolved in $\mathrm{NH}_{3}(\sim 30$ $\mathrm{mL})$ and appropriate amount of $\mathrm{Na}(\sim 0.4 \mathrm{~g})$ was added to achieve blue colour of the solution. The mixture was stirred for $0.5 \mathrm{~h}$ then $\mathrm{NH} 3$ was allowed to escape. The residue was dissolved in $\mathrm{MeOH}$, neutralized with DOWEX to $\mathrm{pH}$ 8, filtered and concentrated. The product was dried and acetylated with $\mathrm{Ac}_{2} \mathrm{O}(20 \mathrm{~mL})$ in pyridine $(20 \mathrm{~mL})$. After $16 \mathrm{~h}$ the reaction was quenched with $\mathrm{MeOH}$, concentrated, co-evaporated with toluene 3 times and dried. Chromatography of the residue on silica gel with hexane : acetone $=55: 45$ gave 9 (1.66 g, 72\%).

1-acetamido-1-deoxy-2,3,6-tri-O-acetyl-4-O-[2-O-(2-hydroxyethyl)-3,6-di-O-acetyl-4-O(2,3,4,6-tetra-O-acetyl- $\alpha$-D-galactopyranosyl)- $\beta$-D-galactopyranosyl]- $\beta$ - $D$ -

glucopyranose (10)

A solution of 9 (1.66 g, $1.54 \mathrm{mmol})$ in $80 \% \mathrm{AcOH}$ was stirred for $1 \mathrm{~h}$ at $90^{\circ} \mathrm{C}$ then concentrated, diluted with DCM, washed with saturated solution of $\mathrm{NaHCO}_{3}$ and concentrated. The residue was dissolved in DCM $(10 \mathrm{~mL})$ and a solution of $\mathrm{NaiO}_{4}(0.7 \mathrm{~g})$ in water ( $3 \mathrm{~mL}$ ) was added. After TLC indicated complete conversion into an aldehyde, NaBH4 (0.5 g) was carefully added under controlled $\mathrm{pH} \sim 7-8$, which was adjusted by addition of portions of AcOH. The mixture was diluted with brine, extracted with DCM 3 times and concentrated. Chromatography of the residue on silica gel in toluene - acetone (75 : 35 - 60 : 40) to gave 10 (1.3 g, 87\%). ${ }^{1} \mathrm{H}-\mathrm{NMR}\left(\mathrm{CDCl}_{3}\right): \delta 6.14\left(\mathrm{~d}, 1 \mathrm{H}, \mathrm{J}_{1, \mathrm{NH}} 9.3\right.$

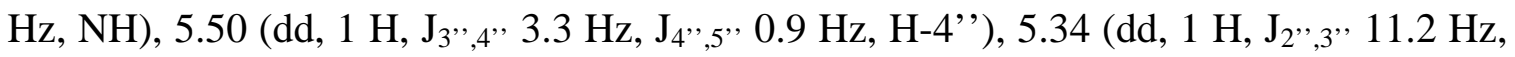

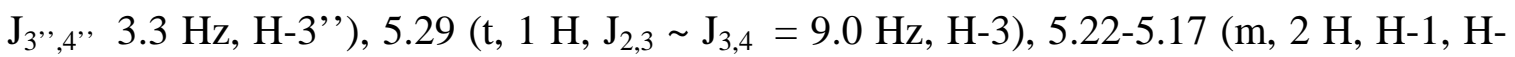
2'), 4.97 (d, 1 H, J', ,2, 3.7 Hz, H-1'), 4.82 (t, 1 H, J $\mathrm{J}_{1,2} \sim \mathrm{J}_{2,3}=9.7 \mathrm{~Hz}, \mathrm{H}-2$ ), 4.71 (dd, 1 H, J', ${ }^{\prime}, 10.4$ Hz, J', 2.7 Hz, H-3'), 4.48 (dd, 1 H, J Ja,6b 11.9 Hz, J Ja,5 0.9 Hz, H-6a), 
4.41-4.37 (m, 2 H, H-6’a, H-5’’), 4.30-4.26 (m, 2 H, H-1', H-6b), 4.15 (dd, J6,'a,6”'b 11.0 Hz, J6"a,5’ 5.7 Hz, H-6’’a), 4.10-4.06 (m, 2 H, H-6’a, H-6’’b), 4.00 (d, 1 H, H-4'), 3.833.61 (m, 7 H, H-4, H-5, H-5', $\mathrm{CH}_{2}$ ), 3.46 (dd, 1 H, H-2'), 2.12, 2.11, 2.09, 2.07, 2.06, 2.05, 2.038, 2.035 (8s, 24 H, Ac), 1.96 (s, 6 H, Ac).

1-acetamido-1-deoxy-2,3,6-tri-O-acetyl-4-O-\{2-O-[2-(p-

nitrophenyloxycarbonyloxy)ethyl]-3,6-di-O-acetyl-4-O-(2,3,4,6-tetra-O-acetyl- $\alpha$-Dgalactopyranosyl)- $\beta$-D-galactopyranosyl $\}-\beta$-D-glucopyranose (11)

To a solution of 10 (2.4 g, $2.48 \mathrm{mmol}$ ) and 4-nitrophenyl chloroformate (0.75 g, 1.5 eq.) in dry DCM $(10 \mathrm{~mL})$ pyridine $(05 \mathrm{~mL})$ was added After 20 min at RT the reaction was quenched with $\mathrm{MeOH}$, diluted with DCM and washed with brine. Chromatography of the residue on silica gel with pentane - ethyl acetate (60:40-40:60) gave 11 (2.4 g, 85\%) ${ }^{1} \mathrm{H}$ -

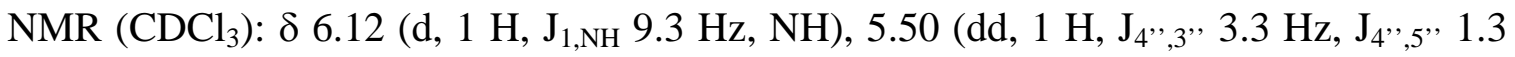

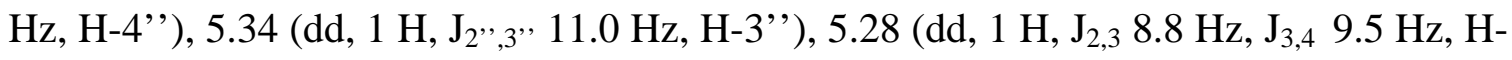
3), 5.21-5.16 (m, 2 H, H-1, H-2’’), 4.98 (d, 1 H, J ${ }_{1}$, ,2, 3.7 Hz, H-1’’), 4.82 (t, 1 H, J,2 $\left.\mathrm{J}_{2,3}=9.5 \mathrm{~Hz}, \mathrm{H}-2\right), 4.76$ (dd, 1 H, J $2^{\prime}, 3^{\prime} 10.4 \mathrm{~Hz}, \mathrm{~J}_{3^{\prime}, 4^{\prime}} 6.9 \mathrm{~Hz}, \mathrm{H}-3$ ’), 4.56 (dd, 1 H, J $6 \mathrm{a}, 6 \mathrm{~b}$ 13.3 Hz, J6a,5 1.8 Hz, H-6a), 4.42-4.36 (m, 3 H, H-5’’, H-6’a, H-6’b), 4.33 (ddd, 1 H, J 2.8 Hz, J 6.4 Hz, J 9.0 Hz, CH2), 4.30 (s, 1 H, H-1'), 4.26 (dd, 1 H, J6b,5 4.6 Hz, H-6b),

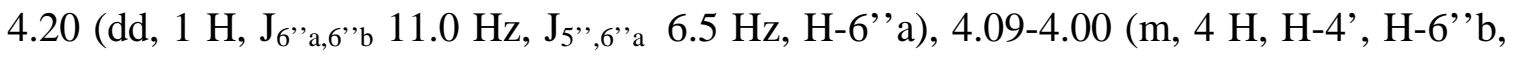
CH $\mathrm{CH}_{2}$ ), 3.92 (ddd, 1 H, J 2.6 Hz, J 6.2 Hz, J 11.5 Hz, CH 2 ), 3.80 (ddd, 1 H, J4,5 9.9 Hz, H5), 3.77 (t, $1 \mathrm{H}, \mathrm{H}-4$ ), 3.67 (t, 1 H, J J',6'a $~$ J $_{5^{\prime}, 6^{\prime} \mathrm{b}} 7.0 \mathrm{~Hz}, \mathrm{H}-5$ '), 3.42 (dd, 1 H, H-2’), 2.14, 2.13, 2.07, 2.06, 2.05, 2.05, 2.035, 2.029, 1.97, 1.96 (10 s, 30 H, Ac).

1,3-di-(t-butoxycarbonylamino)-2-hydroxypropane (13).

To a solution of 1,3-di-amino-2-hydroxypropane 12 (2.13 g, $23.64 \mathrm{mmol}$ ) in DCM (20 $\mathrm{ml}$ ) and $\mathrm{MeOH}(20 \mathrm{ml})$ di-t-butyl dicarbonate $(10.31 \mathrm{~g}, 47.26 \mathrm{mmol})$ was added. The mixture was stirred for $1 \mathrm{~h}$ then concentrated. Chromatography of the residue on silica gel with DCM-MeOH (5\%) gave the title product (6.55 g, $95 \%) .{ }^{1} \mathrm{H}-\mathrm{NMR}\left(\mathrm{CDCl}_{3}\right)$ : $\delta$ 5.13 (broad s, 2 H, NH), 3.71 (p, 1 H, ${ }^{3} \mathrm{~J} 4.6$ Hz, CH), 3.4-3.2 (m, $1 \mathrm{H}, \mathrm{OH}$ ), 3.22 (dd, 2 $\mathrm{H},{ }^{2} \mathrm{~J} 14.2 \mathrm{~Hz}, \mathrm{CH}_{2}$ ), 3.14 (dd, $2 \mathrm{H}, \mathrm{CH}_{2}$ ), 1.41 (s, $18 \mathrm{H}, \mathrm{CH}_{3}$ ).

1,3-di-(t-butoxycarbonylamino)-2-(4-nitrophenyl-carbonyloxy)-propane (14).

To a solution of 13 (3.57 g, $12.29 \mathrm{mmol}$ ) in dry Py a solution of 4-nitrophenylchloroformate (3 g, $14.7 \mathrm{mmol})$ in DCM (5 ml) was added. The mixture was stirred at 
$60 \mathrm{oC}$ for $1 \mathrm{~h}$ then concentrated, co-evaporated with toluene. Chromatography of the residue on silica gel with hexane-acetone (60:40) gave the title product (4.36 g, 78 \%). ${ }^{1} \mathrm{H}-\mathrm{NMR}$

1,3-di-(t-butoxycarbonylamino)-2-[N-(10-carboxydecyl)carbamoyloxy]-propane (15).

To a solution of 14 (1.87 g, $4.1 \mathrm{mmol})$ and 11-amino-undecanoic acid (1.65 g, $8.2 \mathrm{mmol})$ in THF (20 ml) triethylamine $(2 \mathrm{ml})$ was added. The mixture was refluxed overnight then concentrated. Chromatography of the residue on silica gel with DCM-MeOH (4\%) gave the title product (1.0 g, 47\%). ${ }^{1} \mathrm{H}-\mathrm{NMR}\left(\mathrm{CD}_{3} \mathrm{OD}\right): \delta$ 6.7-6.5 (m, $\left.1 \mathrm{H}, \mathrm{NH}\right), 4.7$ (broad s, 2 $\mathrm{H}, \mathrm{NH}$ ), 3.3-3.2 (m, $\left.5 \mathrm{H}, \mathrm{CH}_{2}, \mathrm{CH}\right), 3.07$ (t, $\left.2 \mathrm{H},{ }^{3} \mathrm{~J} 6.7 \mathrm{~Hz}, \mathrm{CH}_{2} \mathrm{COOH}\right), 2.26$ (t, $2 \mathrm{H},{ }^{3} \mathrm{~J}$ $7.5 \mathrm{~Hz}, \mathrm{CH}_{2} \mathrm{~N}$ ), 1.59 (m, $2 \mathrm{H}, \mathrm{C}_{2} \mathrm{CH}_{2} \mathrm{COOH}$ ), 1.5-1.3 (m, $14 \mathrm{H}, \mathrm{CH}_{2}$ ), 1.41 (s, $18 \mathrm{H}$, $\left.\mathrm{CH}_{3}\right)$.

1,3-Bis-\{1-acetamido-1-deoxy-2,3,6-tri-O-acetyl-4-O-[3,6-di-O-acetyl-4-O-(2,3,4,6tetra-O-acetyl- $\alpha$-D-galactopyranosyl)- $\beta$-D-galactopyranosyl]- $\beta$-D-glucopyranose-2'yloxyethyl\}oxycarbamoyl-2-[N-(10-carboxydecyl)carbamoyloxy]-propane (16).

Compound 15 (115 mg, $0.222 \mathrm{mmol}$ ) was dissolved in TFA (1 mL). After $1 \mathrm{~h}$ the mixture was concentrated, co-evaporated with water, freeze-dried from water to give $120 \mathrm{mg}$ of TFA salt. To this product a solution of activated carbonate $11(600 \mathrm{mg}, 0.53 \mathrm{mmol})$ in dry MeCN (4 mL) and triethylamine $(0.2 \mathrm{~mL})$ was added. The mixture was sonicated and heated at $80{ }^{\circ} \mathrm{C}$ overnight then concentrated. Chromatography of the residue on silica gel with DCM-MeOH (10\%) gave the title product (391 mg, 76\%). ${ }^{1} \mathrm{H}-\mathrm{NMR}\left(\mathrm{CD}_{3} \mathrm{OD}\right): \delta$

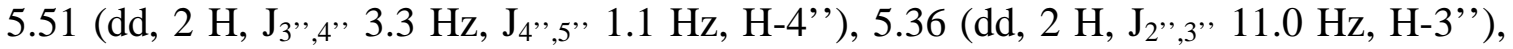
5.29-5.24 (m, 4 H, H-1, H-3), 5.19 (dd, 2 H, J J',2, 3.5 Hz, H-2’’), 5.02 (d, 2 H, H-1'’), 4.93 (t, 2 H, J ${ }_{1,2} \sim \mathrm{J}_{2,3} \sim 9.7$ Hz, H-2), 4.83-4.80 (m, 2 H, H-3'), 4.59 (dd, 2 H, J 6a,6b 12.2 Hz, J6a,5 1.2 Hz, H-6a), 4.41-4.37 (t, 2 H, H-5’’), 4.45-4.42 (m, 4 H, H-1', H-6b), 4.284.08 (m, 14 H, H-4', CH 2 , H-6’a, H-6’b, H-6’’a, H-6’’b), 3.94-3.83 (m, 10 H, H-4, H-5, H-5’, $\mathrm{CH}_{2}$ ), 3.5 (m, 2 H, H-2'), 3.4-3.26 (m, 5 H, CH, $\mathrm{CH}$ ), 3.08 (t, 2 H, J 7.1 Hz, $\mathrm{CH}_{2}$ ), 2.26 (t, 2 H, J 7.5 Hz, $\mathrm{CH}_{2}$ ), 2.13, 2.13, 2.08, 2.07, 2.07, 2.04, 2.03, 2.00, 1.95, 1.94 (10 s, $60 \mathrm{H}, \mathrm{Ac}), 1.61-1.56$ (m, $\left.2 \mathrm{H}, \mathrm{CH}_{2}\right), 1.50-1.44$ (m, $\left.2 \mathrm{H}, \mathrm{CH}_{2}\right)$, ), 1.34-1.28 (m, $12 \mathrm{H}$, $\mathrm{CH}_{2}$ ), 
A solution of 1,2,3,4,6-penta-O-allyl- $\beta$-D-glycopyranose 17 (500 mg, $1.31 \mathrm{mmol}$ ) and 2aminoethanethiol hydrochloride $(1.1 \mathrm{~g}, 9.68 \mathrm{mmol})$ in degassed $\mathrm{MeOH}(5 \mathrm{ml})$ was irradiated at $254 \mathrm{~nm}$ for $20 \mathrm{~h}$. The mixture was concentrated and the residue was purified by size-exclusion chromatography using Sephadex G-10 with water as an eluent to give the title compound (1.01 g, 81\%). ${ }^{1} \mathrm{H}-\mathrm{NMR}\left(\mathrm{D}_{2} \mathrm{O}\right): \delta 4.46$ (d, $\left.1 \mathrm{H}, \mathrm{J}_{1,2} 8.1 \mathrm{~Hz}, \mathrm{H}-1\right)$, 4.023.64 (m, 22 H, H-6a, H-6b, $\mathrm{CH}_{2} \mathrm{O}, \mathrm{CH}_{2} \mathrm{~N}$ ), 3.51 (ddd, 1 H, J5,4 7.3 Hz, J5,6a 2.0 Hz, J5,6b $5.1 \mathrm{~Hz}, \mathrm{H}-5), 3.43$ (t, $\left.1 \mathrm{H}, \mathrm{J}_{3,4} \sim \mathrm{J}_{3,2} 9.5 \mathrm{~Hz}, \mathrm{H}-3\right), 3.34$ (t, $\left.1 \mathrm{H}, \mathrm{H}-4\right), 3.26-3.30$ (m, $10 \mathrm{H}$, $\mathrm{CH}_{2} \mathrm{~N}$ ), 3.14 (dd, 1 H, J J,3 $\left.9.3 \mathrm{~Hz}, \mathrm{H}-2\right)$ 2.90-2.84 (m, $10 \mathrm{H}, \mathrm{CH}_{2} \mathrm{~S}$ ), 2.72-2.65 (m, $10 \mathrm{H}$, $\mathrm{CH}_{2} \mathrm{~S}$ ), 1.99-1.89 (m, $10 \mathrm{H}, \mathrm{CH}_{2} \mathrm{C}_{2} \mathrm{CH}_{2}$ ).

1,2,3,4,6-penta-O-[7-aza-6-(t-butoxycarbonylamino)- $\quad$ 8-oxo-4-thia-nonyl]- $\beta$-Dglycopyranose (19). To a suspension of $18(759 \mathrm{mg}, 0.803 \mathrm{mmol})$, TBTU (1.91 g, 5.96 mmol), HOBt (974 mg, $5.6 \mathrm{mmol}$ ) and N-(t-butoxycarbonyl)-glycine (1.04 g, 5.93) in dry DCM (5 ml) 4-ethyl-morpholine (1.37 g, $11.9 \mathrm{mmol}$ ) was added. When all components were dissolved, the reaction mixture was washed with water and concentrated. Chromatography of the residue on silica gel with DCM-MeOH (5-7\%) gave the title product (1.02 g, 82\%). ${ }^{1} \mathrm{H}-\mathrm{NMR}\left(\mathrm{CDCl}_{3}\right): \delta$ 7.1-6.8 (m, $\left.5 \mathrm{H}, \mathrm{NH}\right), 5.8-5.2(\mathrm{~m}, 5 \mathrm{H}, \mathrm{NH})$, 4.18 (d, 1 H, J $\mathrm{J}_{1,2} 7.8 \mathrm{~Hz}, \mathrm{H}-1$ ), 3.76 (s, 10 H, $\mathrm{CH}_{2}$ of Gly), 4.0-3.4 (m, $23 \mathrm{H}, \mathrm{H}-5, \mathrm{H}-6 \mathrm{a}$, H-6b, $\mathrm{CH}_{2} \mathrm{O}, \mathrm{CH}_{2} \mathrm{~N}$ ), 3.22-3.18 (m, $\left.2 \mathrm{H}, \mathrm{H}-3, \mathrm{H}-4\right), 3.00$ (t, $\left.1 \mathrm{H}, \mathrm{H}-2\right)$ 2.7-2.5 (m, $20 \mathrm{H}$, $\mathrm{CH}_{2} \mathrm{~S}$ ), 1.9-1.8 (m, $\left.10 \mathrm{H}, \mathrm{CH}_{2} \mathrm{C}_{2} \mathrm{CH}_{2}\right), 1.43\left(\mathrm{~s}, 40 \mathrm{H}, \mathrm{CH}_{3}\right)$. 


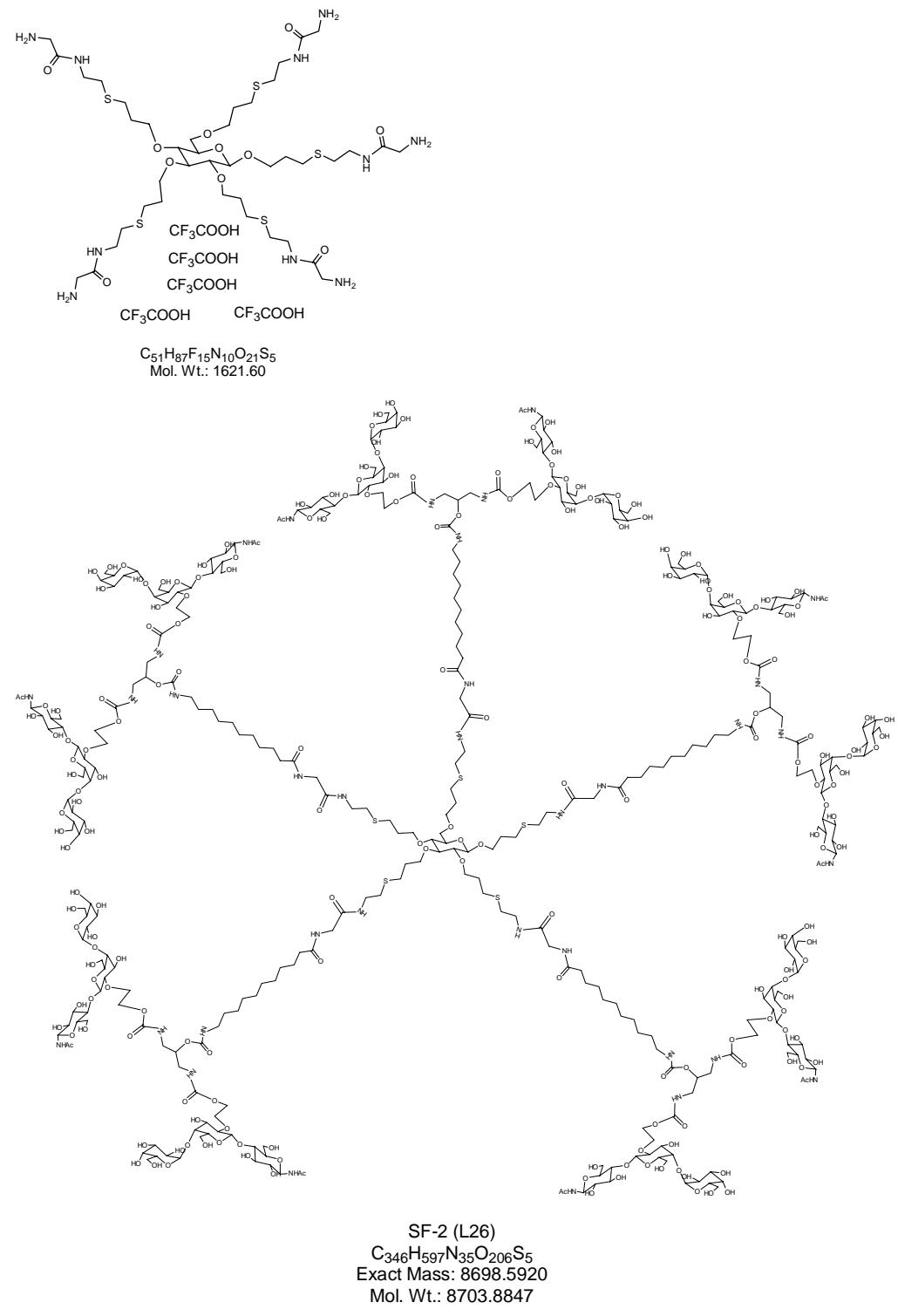

SF-2

Amine salt, obtained from PK-11 (23 mg, $14.2 \mu \mathrm{mol}$ ) was mixed with PK-41 (190 mg, 82 $\mu \mathrm{mol}$ ) TBTU (45 mg), HOBt (22 mg) and dissolved in dry DMF (5 mL). The mixture was stirred overnight at $60^{\circ} \mathrm{C}$, then concentrated, dissolved in $\mathrm{MeOH}$ and solution of $\mathrm{NaOH}$ in $\mathrm{MeOH}$ was added. The mixture was neutralized with $\mathrm{AcOH}$ and the product was purified on HPLC C-18 column. The compound eluted with 60-70\% $\mathrm{MeOH}$. to give SF-2 (84 mg, $2.4 \mu \mathrm{mol}, 68 \%)$. 